\title{
Intervention for Autistic Spectrum Disorders
}

\author{
Pauline A. Filipek, ${ }^{* \dagger}$ Robin Steinberg-Epstein, ${ }^{* *}$ and Teri M. Book ${ }^{* \dagger}$ \\ *Department of Pediatrics, ${ }^{\dagger}$ Divisions of Child Neurology and ${ }^{\star}$ Developmental and Behavioral Pediatrics, University of \\ California, Irvine, School of Medicine, Irvine, California 92868
}

\begin{abstract}
Summary: A comprehensive approach to the assessment of any child with autism must be matched specifically to each individual child and family. This premise holds for medical therapies and special education services as well as psychopharmacologic interventions. Behavioral, as opposed to pharmacologic, treatment is the hallmark of effective intervention for autism. Physicians involved in the care of children with autism need to become familiar with educational law and intervention recommendations. Goals should include improved functional verbal and nonverbal communication and social skills, increased engagement in developmentally appropriate activities, improved fine and gross motor skills, and the development of independent academic and organizations skills, as well as replacement of problem behaviors with developmentally appropriate behaviors.. Medicating children with autism is difficult, but is often
\end{abstract}

necessary for chronic behavioral difficulties. In the absence of clear and present guidelines, we have attempted to use evidence and clinical experience to suggest an algorithm based on symptom clusters. Although children with autism may be responsive to medications at lower doses and more susceptible to side effects than other children, medical intervention can produce a significant improvement in the quality of life for the child and family. Careful thought leading to correct identification of target behaviors can appropriately direct better alternatives for medication. Although these approaches are costly and time-consuming endeavors, the expenditure of such efforts is the only available pathway to improve the potential outcomes for individuals with autism as well as decrease the lifetime societal costs for each individual. Key Words: Autism, treatment, intervention, special education, psychopharmacology, IDEA.

\section{WHAT IS AUTISM?}

The synonymous terms Autistic Spectrum Disorders (ASD) and Pervasive Developmental Disorders (PDD) refer to a wide continuum of associated cognitive and neurobehavioral disorders, defined by, but not limited to, three core features: 1) qualitative impairments in socialization, 2) qualitative impairments in verbal and nonverbal communication, and 3) restricted and repetitive patterns of behaviors, interests, or activities. ${ }^{1}$ Autism was formally described over 60 years ago by Kanner, ${ }^{2}$ and portrayals exist of autistic individuals in the 19th century. ${ }^{3,4}$ However, our understanding of this complex disorder has emerged only over the past 25 years, and, despite the recent intense focus, it continues to be an art and science in rapid evolution. Many terms have been used over the years to refer to these disorders, e.g., childhood schizophrenia and autistic psychoses. ${ }^{5,6}$ In

Address correspondence and reprint requests to Pauline A. Filipek, M.D., UC Irvine School of Medicine, Director, For OC Kids, 1915 West Orangewood, Suite 200, Orange, CA 92868-2057. E-mail: ForOCKids@uci.edu.
1980, the third edition of the Diagnostic and Statistical Manual (DSM) $)^{7}$ created an umbrella diagnosis of PDD, which included, for the first time, the term Infantile Autism; autism was also clearly differentiated from childhood schizophrenia and other psychoses for the first time, and the absence of psychotic symptoms, such as delusions and hallucinations, became one of the six diagnostic criteria. The revised DSM-IIIR ${ }^{8}$ broadened the PDD spectrum in 1987 and narrowed the possible diagnoses to two, Autistic Disorder and Pervasive Developmental Disorder-Not Otherwise Specified (PDD-NOS). Since 1994, the DSM-IV ${ }^{1}$ has included five possible diagnoses under the PDD umbrella (see Table 1), which are concordant with the World Health Organization's International Classification of Disease, 10th edition. ${ }^{9}$

The terms autism, autistic, and ASD are used interchangeably throughout this paper and refer to the broader umbrella of PDD, whereas the specific term Autistic Disorder is used in reference to the more restricted criteria as defined by the DSM-IV. ${ }^{1}$ The complexity and wide variability of symptoms within the autistic spectrum point to multiple etiologies that are currently 
TABLE 1. Diagnostic Nosology According to DSM-IV $V^{l}$

Pervasive Developmental Disorders

\begin{tabular}{|c|c|c|c|c|}
\hline Autistic & Asperger & Rett & Childhood & PDD-NOS \\
\hline Disorder & Disorder & Syndrome & $\begin{array}{l}\text { Disintegrative } \\
\text { Disorder }\end{array}$ & Atypical Autism \\
\hline
\end{tabular}

grouped together under this diagnostic umbrella because of the similar core behavioral symptomatology. The ASDs are not rare disorders, but instead are more prevalent in the pediatric population than cancer, diabetes, spina bifida, and Down syndrome. The earliest epidemiology studies noted a prevalence of Infantile Autism of 4 to 5 per 10,000 , which is approximately 1 in every 2000 people. ${ }^{10}$ With the broader clinical phenotype and improved clinical recognition, the prevalence estimates have increased to $\sim 60$ to 70 per 10,000 or almost $1 \%$ of the population. ${ }^{11-13}$ These higher prevalence rates imply that there are over 500,000 children under 18 years of age in the United States who meet diagnostic criteria for autism. $^{14}$

The overall ratio of males to females with autism has traditionally been reported at approximately $3: 1-4: 1^{10}$; however, the ratio seems to vary with intelligence quotient (IQ), ranging from 2:1 with severe mental retardation to more than $4: 1$ in those with average IQ. ${ }^{15-17}$ Some feel that fewer females with normal IQ are diagnosed with autism because they may be more socially adept than males with similar IQ. ${ }^{18,19}$

\section{The broader phenotype}

Although Allen ${ }^{20}$ first coined the phrase "autistic spectrum disorder"; and Wing ${ }^{21}$ wrote about the "autistic continuum" in 1988, controversy still surrounds this concept of a broader clinical phenotype. Over the past 15 years, there has been a slowly growing clinical consensus that the umbrella of "pervasive developmental disorders" does actually represent an "autistic spectrum" "22; Also, for the first time, DSM-IV criteria includes the term qualitative to describe the impairments within the major criteria, defining a range of impairments rather than the absolute presence or absence of a particular behavior as sufficient to meet a criterion for diagnosis.

The currently recognized clinical phenotype includes children with milder, but nonetheless unequivocal, social, communication, and behavioral deficits. Many highfunctioning autistic children are diagnosed after presentation to clinics specializing in learning disabilities or Attention-Deficit/ Hyperactivity Disorder (ADHD). ${ }^{23}$ Almost $15 \%$ of previously undiagnosed children receiving special education services met criteria for DSM-IIIR Autistic Disorder in one series. ${ }^{24}$ Autistic "traits" were also retrospectively found in almost one-quarter of 2201 adults previously diagnosed with various learning dis- abilities. ${ }^{25}$ Questionnaires devised to specifically diagnose ADHD will not identify autistic symptomatology, and $74 \%$ of children with high-functioning autism in another series had erroneously been previously diagnosed with ADHD despite clear differences in their social competence, cognitive development, and restricted range of activities. ${ }^{26}$

\section{Signs and symptoms of autism}

All individuals on the autistic spectrum demonstrate qualitative deficits in 1) reciprocal social interactions and 2) verbal and nonverbal communication, with 3) restricted and repetitive behaviors or interests. ${ }^{1}$ There is, nonetheless, marked variability in the severity of symptomatology across patients, and the level of intellectual function can range from profound mental retardation through the superior range on conventional IQ tests. A discussion of autistic behaviors is not within the scope of this paper, and interested readers are referred to recent in-depth reviews. ${ }^{27-29}$

\section{THERAPEUTIC INTERVENTIONS FOR AUTISM}

\section{Behavioral interventions}

Behavioral, as opposed to pharmacologic, treatment is the hallmark of effective intervention for everyone with autism. This includes the more traditional languagecommunication therapies, occupational and sensory integration therapies, as well as regular and special education services, and the various therapies comprised under the constructs of applied behavioral analysis, which has garnered favor more recently. Although most physicians might feel that the information that follows is "outside the scope of their practices," it is becoming increasingly imperative that both primary care and specialty physicians act as advocates for their pediatric patients. Therefore, every physician who treats children with autism or any other developmental disorder should be at least familiar with current educational law and special education recommendations to best serve their vulnerable patient population.

The first key federal legislation addressing special education was the Education of All Handicapped Children Act (Public Law 94-142) in 1975. This legislation has been amended many times and since 1997 carries the title of Individuals with Disability Education Act (IDEA) 
TABLE 2. Treatment Algorithm

\begin{tabular}{|c|c|c|c|c|c|}
\hline \multirow{2}{*}{$\begin{array}{c}\text { Associated Behaviors } \\
\text { What Appears as }\end{array}$} & \multirow{2}{*}{$\frac{\text { Cluster }}{\text { May Actually Be }}$} & \multicolumn{4}{|c|}{ Psychopharmacologic Approach } \\
\hline & & \multirow{2}{*}{$\begin{array}{l}\text { Approach } \\
\text { First line: }\end{array}$} & \multirow{2}{*}{$\begin{array}{l}\text { Class of Medication } \\
\text { SSRI* }\end{array}$} & \multicolumn{2}{|c|}{ Medication and Recommended Starting Dose } \\
\hline Rigidity/opposition & $\begin{array}{c}\text { Anxiety and/or } \\
\text { Compulsion }\end{array}$ & & & Fluoxetine & $4 \mathrm{mg} /$ day \\
\hline Obsessive behaviors & & & & Escitalopram & $2.5 \mathrm{mg} /$ day \\
\hline Compulsive behaviors & & Second line: & Atypical neuroleptic & Risperidone & $0.25 \mathrm{mg}$ at bedtime \\
\hline Rituals & & & & Aripiprazole & $2.5-5 \mathrm{mg} /$ day \\
\hline \multicolumn{6}{|l|}{ Transitional issues } \\
\hline Difficulty shifting attention & & & & & \\
\hline Overattention to inconsequentia & & & & & \\
\hline
\end{tabular}

Overattention to inconsequential things

\begin{tabular}{|c|c|c|c|c|}
\hline $\begin{array}{l}\text { Hyperactivity } \\
\text { Impulsivity } \\
\text { Over-reactivity }\end{array}$ & Hyperactivity & First line & Stimulants & $\begin{array}{l}\text { Methylphenidate, dextroamphetamine, amphetamine salts, } \\
\text { ordexmethylphenidate } \sim 50 \% \text { of lowest available dose } \\
\text { while keeping integrity of preparation }\end{array}$ \\
\hline
\end{tabular}

Over-reactivity

Aggression

Agitation

Irritability
Second line

Third line $\alpha-2$ agonists

Atypical neuroleptic

$\mathrm{SNRI}+$

Attention Deficit First line

Second line

Stimulant

"Auditory processing" deficits

Social aloofness

"In their own world"

"Not connected"

Daydreams

Distracted while keeping integrity of preparation

Clonidine $\quad 0.05 \mathrm{mg}$ at bedtime

Risperidone $\quad 0.25 \mathrm{mg}$ at bedtime

Aripiprazole 2.5-5 mg/day

Atomoxetine $\quad \leq 40 \mathrm{~kg}, 10 \mathrm{mg} /$ day

$>40 \mathrm{~kg}, 18 \mathrm{mg} / \mathrm{day}$

Atomoxetine

$\leq 40 \mathrm{~kg}, 10 \mathrm{mg} / \mathrm{day}$

$>40 \mathrm{~kg}, 18 \mathrm{mg} /$ day

Methylphenidate, dextroamphetamine, amphetamine salts, or Dexmethylphenidate $\sim 50 \%$ of lowest available dose while keeping integrity of preparation
Not completing tasks

Atypical neuroleptic

SSRI

Third line

Social aloofness

Expressive language deficit

Pragmatic language deficit

Cognitive distortion

Lack of drive to socially interact

First line

\section{Social}

Second line

Second line

Third line

Risperidone
Aripiprazole
Fluoxetine
Escitalopram
Fluoxetine
Escitalopram
Atomoxetine
Risperidone
Aripiprazole

$0.25 \mathrm{mg}$ at bedtime

$2.5-5 \mathrm{mg} / \mathrm{day}$

$4 \mathrm{mg} / \mathrm{day}$

$2.5 \mathrm{mg} /$ day

$4 \mathrm{mg} / \mathrm{day}$

$2.5 \mathrm{mg} / \mathrm{day}$

$\leq 40 \mathrm{~kg}, 10 \mathrm{mg} /$ day

$>40 \mathrm{~kg}, 18 \mathrm{mg} / \mathrm{day}$

$0.25 \mathrm{mg}$ at bedtime

$2.5-5 \mathrm{mg} / \mathrm{day}$

$\mathrm{SSRI}=$ selective serotonin reuptake inhibitor; $\mathrm{SNRI}=$ selective norepinephrine reuptake inhibitor.

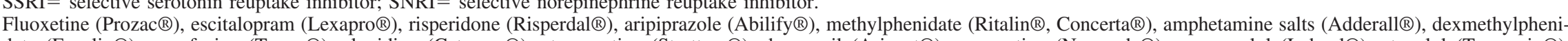

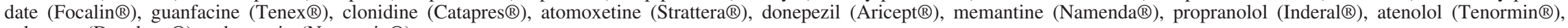
valproate (Depakote $\left.{ }^{\circledR}\right)$, gabapentin (Neurontin $\left.{ }^{\circledR}\right)$. 
(Public Law 105-17), which can be reviewed at http:// www.nectac.org/idea/pl105-17.asp and includes the following major standards ${ }^{30}$ :

1) Zero Reject: All students with disabilities must be provided a free and appropriate public education (FAPE).

2) Nondiscriminatory Evaluation: Each student must receive a full individual examination before being placed in a special education program, with tests appropriate to the individual's cultural and linguistic background.

3) Individualized Education Plan (IEP): Every student must have an individualized education plan which must describe the current performance level and goals for the school year, the particular special education services to be delivered, and the procedures by which outcomes are evaluated. . . A companion bill for infants and toddlers with disabilities (Public Law 99-457) has a similar provision to the IEP for an Individual Family Service Plan (IFSP) for children from birth to age three years [sic. Early Intervention, EI].

4) Least Restrictive Environment: As much as possible, children with disabilities must be educated with children without disabilities. The educational philosophy is to move children with special needs as close to the normal setting (regular classroom) as feasible.

5) Due Process: Due process is a set of legal procedures to ensure the fairness of educational decisions and the accountability of both professionals and parents in making those decisions.

6) Parental Participation: Parents are to be included in the development of the IEP, and they have the right to access their child's educational records (pp 177-179). ${ }^{30}$

In 2000, the National Academies of Sciences convened a Committee on Educational Interventions for Children with Autism at the request of US Department of Education Office of Special Education Services. The committee was charged to examine the empiric evidence pertinent to educational (behavioral) interventions for children with autism from birth to age 8 years by examining the scientific literature as well as commissioned papers ${ }^{31}$ addressing science and policy issues. The findings of the committee were published as a monograph, ${ }^{30}$ which is also available to the interested reader at http:// www.nap.edu/books/0309072697/html/.

As all ASDs share the same three core deficits, individual differences in language development, verbal and nonverbal communication, sensory-motor skills, adaptive behavior, and cognitive abilities should be consid- ered more important for treatment goals and strategies than the specific diagnosis within the autistic spectrum. Therefore, any child on the autistic spectrum should be eligible for special services within the educational category of autism instead of other terminology such as other health impaired, social-emotional disturbed, or neurologically impaired. The assessment for ASD should involve a multidisciplinary approach and include evaluations of social behavior, language and communication (not simply speech and articulation), adaptive behavior, motor skills, atypical behaviors, and cognitive status by a team experienced in the assessment of children with autism. Parents should not be expected to provide the majority of educational programming, but their concerns and perspectives should be included in the educational planning. Local school districts should provide families with enough information for them to be effective members of the team. Before the IEP meeting, parents should receive written results of the assessment and contacts to explain the findings, so they can participate in the actual educational placement discussions with prior knowledge and understanding of their child's strengths and weaknesses; too often parents are so confused by the unanticipated low scores on the testing battery that they are unable to fully comprehend the remainder of the IEP meeting. As part of the IEP, parents should be given the chance to learn the necessary techniques for teaching their child new skills and reducing problem behaviorsboth by didactic sessions and ongoing consultations through the school district. And finally, the committee strongly recommended that parents experiencing excessive stress should have mental health services provided to avoid or ameliorate parental strain leading to separation and divorce as well as other areas of undue tension in the home.

Although recognizing that early intervention and special education services vary considerably across the United States, the committee identified critical aspects of behavioral intervention that should be included in every autistic child's and adolescent's IFSP/IEP under IDEA. Appropriate goals for individuals with ASD should be measurable behaviors that can be accomplished within a year and that can be anticipated to impact a child's involvement in life in general, including, but not limited to:

- Social cognition skills to increase general life participation with family and peers

- Receptive and expressive verbal language skills as well as nonverbal communication skills

- Functional symbolic communication systems as precursor, adjunct, or replacement for spoken language 
- Increased engagement in appropriate developmental activities

- Cognitive skills, including symbolic play, basic concepts, and academic skills

- Fine and gross motor skills used for age-appropriate functional activities

- Replacement of problem behaviors with more conventional appropriate behavior

- Independent organizational skills and other behaviors that ultimately lead to success in regular education classrooms

\section{Pharmacologic intervention}

While behavioral therapies are clearly and without question the interventions of choice for those with autism, there is often a need for psychopharmacologic intervention. Aberrant behaviors may interfere with or impede educational and emotional progress despite Herculean efforts by teachers, therapists, and family members to replace them with more appropriate behaviors. Furthermore, these anomalous behaviors may be so severe or impulsive as to endanger the child's safety and educational placement. Situations like these necessitate the consideration of the use of medications to diminish the behaviors and therefore improve outcomes.

Traditionally, the medical community approaches the treatment of a medical or psychiatric condition by choosing a medication from a class of medications aimed at that disorder with its unique core symptoms (e.g., antidepressants for depression or antipsychotics for schizophrenia). However, there is a dearth of research to support the use of any medication in the treatment of children with autism. There are no US Food and Drug Administration (FDA)-approved drugs for the treatment of "autism" per se. This is, in part, due to the incredible heterogeneity of this disorder. Therefore, pharmacologic intervention in children with autism must instead be targeted toward specific behaviors that significantly interfere with daily function.

Given that there is insufficient information on the vast majority of medications used in children ${ }^{32,33}$ and the long-term effects of any medication on the developing brain is largely unknown, as is the neurochemical basis of autism, psychopharmacology in children with autism must be based on anecdotal experience, existing child and adult literature, and established principles. The only directives are that

1) all potential medical etiologies causing pain or discomfort have been excluded, such as gastroesophageal reflux, sleep disorders, sinusitis, occult otitis media, and even seizure disorders, ${ }^{34}$

2) all behavioral management techniques are attempted before medication is initiated,
3) there remains a clear need for pharmacologic intervention, and

4) the medication management must proceed in a responsible and conscientious manner. ${ }^{32}$

Psychotropic medications are used in children with autism in a predominantly off-label manner. They are usually chosen because they are already in use to treat similar symptoms in other disorders. Examination of the literature sometimes supports their use in autism but is far from convincing. Before presenting recommendations on choices of particular medications, it is important to briefly review the literature on the most commonly used medications: selective serotonin reuptake inhibitors (SSRIs), stimulants, typical and atypical neuroleptics, $\alpha-1$ agonists, selective norepinephrine reuptake inhibitors (SNRIs), and mood stabilizers in children with autism.

\section{Review of the literature}

Overall, there are very few studies with large enough samples to draw reasonable conclusions. Usually these studies are open label (rather than double-blind placebo controlled) and not specific to autism. While one is often tempted to extrapolate from the adult literature, research strongly suggests that adult responses to medications should never be generalized to children. ${ }^{32,35}$ Indeed, it is generally unsound to even extrapolate responses to medications between nonautistic and autistic children. ${ }^{36,37}$ Active research suggests that children with autism tend to have a smaller therapeutic window and that this window is often reached at lower doses than used with typical children. For that reason, one should monitor patients with autism particularly closely.

Recent examinations of current psychopharmacologic usage patterns revealed common themes that should be incorporated into any clinical algorithm. The greater the disability and the more restricted the living situation (e.g., group home), the higher the use of psychotropic medication. Medications used included, in order of frequency, antidepressants, psychostimulants, neuroleptics, and finally, $\alpha$-agonists. Almost half of the subjects were on one medication and almost a third were on two or more medications (usually a neuroleptic and SSRI). The majority (65\%) of psychopharmacologic interventions were used to treat a target symptom of anxiety. In classic Autistic Disorder, neuroleptics tend to be the most commonly used medication. In high functioning autism or Asperger's disorder, the target symptoms are usually different-most commonly attentional problems early in life and anxiety and depression later in life. ${ }^{38,39}$

Before discussing medication management and symptom clusters it is important to understand the body of literature supporting usage in management of autistic 
children. What follows in a compilation of pertinent research in children with autism.

A review of the literature finds that SSRIs, which are the most commonly prescribed medication in the autistic population, have surprisingly little scientific support. For example, the total number of children with autism studied on fluoxetine is 250 , most of which were open label trials. The most comprehensive study was recently published by Hollander et al. ${ }^{40}$ Their double-blind placebocontrolled crossover study of fluoxetine showed improvement in repetitive behaviors and varying effects on other autistic symptomatology. These studies yield encouraging results, but children with autism tended to have lower response rates and more side effects than expected..$^{41}$ Furthermore, many children with autism tend to respond to lower doses of SSRIs than do children with anxiety disorders. Children with autism may also be more prone to the paradoxical response of hyperactivation with SSRIs.

Psychostimulants, another frequently used medication in this population, have also been understudied. Historically, they were believed to exacerbate "classically" autistic behavior. However, more recent studies suggest they may be more helpful in this population. A study of 60 children with autism showed benefit, but they were more vulnerable to side effects and had a lower response rate. ${ }^{42}$ This is further confirmed by a recently published multisite study looking at 72 children with autism; again, they found significant improvement in hyperactivity, but less than seen in typical ADHD, and with higher rates of side effects. ${ }^{43}$

In light of the significant drawbacks associated with traditional neuroleptics/antipsychotics, ${ }^{44,45}$ the newer atypical antipsychotics are being used with more frequency. There are good data to support the use of risperidone in this population. While there are several small open-label studies of risperidone, probably the best evidence comes from the Research Units on Pediatric Psychopharmacology (RUPP) study. ${ }^{46}$ This relatively large $(n=100)$ multicenter study showed a significant improvement in irritability, hyperactivity, and stereotypies in over 100 study subjects. The results also suggest that there may be a place for a trial off of medication after 6 months of stable behavior. However, the study demonstrated significant weight gain as a side effect. ${ }^{46}$ The beneficial response to risperidone was reproduced in another study, which also noted the side effect of significant weight gain. ${ }^{47}$ Despite strong evidence in its favor, the FDA has not felt that the risk/ benefit profile was strong enough to warrant granting risperidone a specific indication for use in autism. There have been only a few small studies looking at any of the other atypical antipsychotics, but some studies are presently underway.

There are only a few autistic patients that have been studied on $\alpha$-agonists and $\beta$-blockers, and none with double-blind placebo-controlled studies. Mood stabilizers appear to be the least-studied medication group in autistic children. Behavioral benefits of valproic scid, lamotrigine, and carbamazepine have been looked at in a small number of patients in combination with epileptic discharges. ${ }^{48,49}$ No clear results were determined. Other studies looking at memantine hydrochloride in children to increase language production are currently underway. A small recently published open-label study suggests improvement in memory symptoms and behavioral manifestations of ASD using memantine. This substantiates the need for more studies with this class of medications. ${ }^{50}$

\section{Treatment algorithm (Table 2)}

From the available literature and using usage patterns the following algorithm was developed. The first step is to prioritize the target symptoms into one of four clusters and to then choose a primary and secondary cluster. Overall, the research that does exist suggests that children with autism may be very sensitive to medications. When starting any medication for this population it is imperative to start with very low dosages and titrate slowly to minimize untoward side effects.

The management strategy proposed here is a conventional one ${ }^{35}$ : to reduce particular target symptoms associated with the diagnosis of autism-inattention, impulsivity, aggression, rigidity, compulsive behaviors, and anxiety. The significant issue in patients with autism is that simply identifying an apparently obvious target symptom is inadequate. With autism, one should try to identify the behavioral origins driving the particular target symptom, to thereby understand its often-obscure etiology; only then can one choose the medication most appropriate for the particular target behavior.

Anxiety/compulsive cluster. In addition to the expected anxiety and compulsions in this cluster, rigidity, oppositionality, depression, and transitional difficulties are included here, because in this population these behaviors often appear to arise from an intense apprehension of the unknown. When a child with autism is challenged (e.g., an unfamiliar rule in a game or a different way of solving a math problem) they become anxious, because the unfamiliar requires effective problem-solving, which is a known area of cognitive weakness in autism. Rather than try the new and uncomfortable action, the child would rather persist in their present and comfortable behavior pattern to the point of opposition. As the pressure to change mounts, so does the anxiety and, ultimately, rigidity. For similar reasons, changing or transitioning from one activity to another can follow a similar pattern; most parents of patients with autism become highly adept at giving repeated timed "warnings" of an impending transition. Medication aimed at reducing anxiety may therefore also produce a previously un- 
available behavioral flexibility. The choice might be affected by the severity of the symptoms, the ability of the parents to wait for the onset of medication effect, as well as the parental ability to deal with potential side effects (e.g., neuroleptics).

Hyperactivity cluster. This cluster captures the often frenetic activity that is expressed as impulsivity, hyperactivity, over-reactivity, mood instability, easy dysregulation, and aggression, when not better explained by an alternate trigger, such as anxiety. When a child presents with a recent exacerbation of these symptoms, it is important to revisit recent changes is the child's life (e.g., a new teacher, new home, vacation, or change in routine). If behavioral remediation doesn't lessen the symptoms or if the problems are longstanding, a trial of medication should be used. If the behaviors are not dangerous to the child or to those around the child, then a trial of traditional stimulants is warranted. However, if the symptoms are severe or paired with anxiety or severe aggression, it is often necessary to combine a stimulant with an SSRI or begin a trial of an atypical antipsychotic medication.

Attention deficit cluster. Although, by definition in the DSM-IV, ${ }^{1}$ individuals with ASD cannot also have ADHD, there is an inherent attention deficit in autism. What may appear at face value to be "ADHD" in a child with autism may well be due to an inability to shift attention (rather than the more traditional executive function deficits seen in $\mathrm{ADHD}^{51}$ ), to overattend or have preoccupations with various obsessions, or to have an auditory processing deficit that precludes effective comprehension of the spoken word. While it is clearly not conventional to describe an apparent deficit in "auditory processing" as a system helped by medication, a theoretical explanation of why medication might be helpful might include increasing working memory as an attempt to lengthen the time that the brain needs to process information. Medication does not cure the problem, but improvement is often reported. While controversial, our experience suggests atomoxetene is an especially good choice if the secondary cluster is anxiety, perhaps because of its early origins as an antidepressant. Atypical neuroleptics alone are good for some forms of inattentiveness that are caused by rigidity, but the side effects of neuroleptics suggest cautious use. SSRIs are only helpful if the inattentiveness is predominantly caused by anxiety or obsessions and compulsions.

Social cluster. This cluster represents the remaining, often core symptoms of autism, which are barriers to mainstream function. They include problems with pragmatic language (social language), understanding nonverbal communication (facial expression, body postures, tone voice, and implied information), receptive and expressive language disorders, cognitive distortion, and lack of drive to pursue social engagement.

While we would like to be able to target these symp- toms directly, at this time there are no medications that specifically treat these symptoms. Our goal then should be to choose a medication for other targets in which the by-product might also be to improve these core symptoms. This cluster is here to remind us that the aim of any medication should be to increase the child's overall functioning. For example, in a child with ADHD-type symptoms and social aloofness, one might choose a norepinephrine reuptake inhibitor over a traditional stimulant because the proposed antianxiety effect of that medication may lead to improved ability to engage and interact with others. Further research is necessary to determine whether these medications indeed can be used to treat social/language symptoms in their own right.

\section{Cases}

The following four cases illustrate target symptoms that, if taken at face value, could mislead the physician and thereby lead to the wrong behavioral cluster being chosen and the choice of a suboptimal medication.

Case 1. Johnny's teacher feels he is "ADHD." He can't sit still. He's always out of his seat picking things off the floor. He's not completing his work and cannot focus on the tasks presented to him. His mother agrees that he just can't sit still. She describes his constant drive to find any and all small items for collection. He is often excited and "hyper" in his pursuit of these items.

In your office, you notice Johnny is on the floor picking up small pieces of lint. He carries a shoebox full of lint with him. He is so driven to this behavior that he is unable to pay attention to what others feel is important (e.g., schoolwork or the office visit).

These target symptoms sound consistent with ADHD, but, in Johnny's case, they may actually be better captured by an anxious or obsessive-compulsive drive. This would move him from the hyperactive cluster to the anxiety cluster. This would then offer an alternative medication guide. Had he stayed in the hyperactive cluster, the medication prescribed might have very well exacerbated these behaviors.

Case 2. Susie's teacher says that Susie is VERY defiant. "She will not do what I ask her. She always has to do it her way." She will even crawl under her desk. She is constantly arguing about rules on the playground. Susie's teacher suggests that she is oppositional and defiant. Her mother also sees these behaviors but knows that when Susie is familiar with the routine and is allowed to make choices things work out okay. She is usually a very nice girl but is having difficulty with peers on the playground. Reading comprehension and written expression are another challenge. Her peers find her "weird" and make fun of her.

Susie is a very sweet, albeit immature, 12-year-old, who sits in your office inappropriately holding her Barbie. She has poor eye contact. She is very cooperative, 
until you ask her to do something new, different, or without warning. Susie then appears stubborn or has outbursts making any type of transition or flexibility very challenging. She becomes very anxious when confronted with anything new.

This description might lead to a diagnosis of oppositional defiant disorder (ODD). However, children with ODD are driven by anger and lack of remorse. The drive for this target behavior appears to be founded in anxiety. This makes ODD unlikely. A more comprehensive explanation leads to a diagnosis of autism and places these target symptoms in the anxiety cluster.

It is no accident that both cases fall into the anxiety cluster. Many children on the spectrum have symptoms related to unrelenting anxiety.

Case 3. Eight-year-old Sammy has struggled with attention issues since kindergarten. The teachers often comment that he appears to be daydreaming, is not accomplishing his tasks, and tends to get "stuck" on a particular component of an assignment. Sammy's mother has to redirect him a great deal, especially when getting him dressed in the morning.

When you talk to Sammy in your office, he intermittently answers your questions without making eye contact. You seem to be able to carry on a conversation with his mother without Sammy even seeming to realize that you are talking about him. He comes across as aloof and a bit odd. His mother reports that the other children like him because he is easy to get along with, but he often wanders away. He seems to be unaware of what goes on around him and to be disconnected from others.

At first glance, one might choose a traditional stimulant to address his symptoms of inattention. However, a more in-depth assessment might suggest a norepinephrine reuptake inhibitor or a combination of a stimulant and an SSRI. In this way, the lack of social connectedness and the possibility of an anxiety component together with inattention can be addressed. Traditional stimulants are not out of the question, but they may lead to more agitation and lability in a child like Sammy compared with a child with uncomplicated attentional issues.

Case 4. Michael is a 5-year-old who is brought in by his mother because his kindergarten teacher reports that he is "out of control." He can't sit still or follow directions. He fidgets with anything and everything. He has kicked the teacher and thrown a chair. At school he has an applied behavioral program in place that has been modified repeatedly to address these symptoms with only minimal improvement.

In the office he is constantly in motion, opens and closes doors and drawers, hits his mother when she won't give him what he wants, curses, and calls her names. At home he hits his 18-month-old brother and when angry throws himself against the wall or down on the floor without regard for his safety. He speaks in single words or two-word phrases but is unable to effectively communicate his needs. The behaviors worsen with a lack of structure and with routine changes in his schedule or environment. There are no outward signs of anxiety.

There is a clear concern for this child's safety and the safety of others. He appears out of control and frenetic in his behavior patterns and is not learning. A milder presentation of these symptoms would suggest the use of a stimulant medication, but in consideration of the safety implications for his brother as well as the child himself, a trial of an antipsychotic might be warranted.

\section{SUMMARY}

A systematic, comprehensive approach to assessment of any child with autism must be developed that is matched specifically to each individual child and family. This same premise holds for the evaluation for and delivery of medical therapies and special education services as well as psychopharmacologic interventions. Behavioral, as opposed to pharmacologic, treatment is the hallmark of effective intervention for autism. Behavioral goals should include improved functional verbal and nonverbal communication and social skills, increased engagement in developmentally appropriate activities, improved fine and gross motor skills, and the development of independent academic and organizational skills, as well as replacement of problem behaviors with developmentally appropriate behaviors. Although this is a costly endeavor, the expenditure of such an effort is the only available pathway to increase the potential outcomes for individuals with autism as well as decrease the lifetime societal costs for each individual.

Medicating children with autism is difficult and once started almost always becomes chronic. Although additional scientific validation is needed to support medication use in children, serious behavior problems exist that need to be addressed. In the absence of clear and present guidelines, we have attempted to use evidence and clinical experience to suggest an algorithm based on symptom clusters. Although children with autism may be more susceptible to side effects and responsive to medications at lower doses compared with other children, medical intervention can make a huge improvement in a quality of life for the child and family. Careful thought leading to correct identification of target behaviors can appropriately direct better alternatives for medication.

Acknowledgments: This work was supported in part by the Children and Families Commission of Orange County, California and the Larry and Helen Hoag Foundation.

\section{REFERENCES}

1. American Psychiatric Association. Diagnostic and statistical manual of mental disorders, Ed 4. Washington, DC: American Psychiatric Association, 1994. 
2. Kanner L. Autistic disturbances of affective contact. Nervous Child 2:217-250, 1943

3. Waltz M, Shattock P, Carrey NJ. Autistic disorder in nineteenthcentury London: three case reports Itard's 1828 memoire on "Mutism caused by a lesion of the intellectual functions": a historical analysis. Autism 8:7-20, 2004.

4. Carrey NJ. Itard's 1828 memoire on "Mutism caused by a lesion of the intellectual functions": a historical analysis. J Am Acad Child Adolesc Psychiatry 34:1655-1661, 1995.

5. American Psychiatric Association. Diagnostic and statistical manual of mental disorders. Washington, DC: American Psychiatric Association, 1952.

6. American Psychiatric Association. Diagnostic and statistical manual of mental disorders, Ed 2. Washington, DC: American Psychiatric Association, 1968.

7. American Psychiatric Association. Diagnostic and statistical manual of mental disorders, Ed 3. Washington, DC: American Psychiatric Association, 1980.

8. American Psychiatric Association. Diagnostic and statistical manual of mental disorders, Ed 3, Revised. Washington, DC: American Psychiatric Association, 1987.

9. World Health Organization. The ICD-10 classification of mental and behavioral disorders: diagnostic criteria for research. Geneva: World Health Organization, 1993.

10. Lotter V. Epidemiology of autistic conditions in young children. I. Prevalence. Soc Psychiatry 1:124-137, 1966.

11. Baird G, Charman T, Baron-Cohen S, Cox A, Swettenham J, Wheelwright $\mathrm{S}$ et al. A screening for autism at 18 months of age: a 6-year follow-up study. J Am Acad Child Adolesc Psychiatry 39:694-702, 2000.

12. Centers for Disease Control and Prevention. Prevalence of autism in Brick Township, New Jersey, 1998: community report. Atlanta, GA: Center for Disease Control and Prevention, 2000.

13. Chakrabarti S, Fombonne E. Pervasive developmental disorders in preschool children. JAMA 285:3093-3099, 2001.

14. US Census Bureau. Fact Sheet: 2004 American community survey data profile highlights, 2005 Available at: http://factfinder.census. gov/servlet/ACSSAFFFacts?_event $=\& g e o \_i d=01000 U S \&$ geo Context $=01000$ US\&_street $=\&$ \&_county $=\&$ _cityTown $=$ \&_state $=$ \&_zip $=$ \&_lang $=$ en\&_sse $=$ on \&ActiveGeoDiv $=$ \&_useEV $=$ \&pctxt $=$ fph\&pgsl $=010$. Accessed January 9, 2006.

15. Bryson SE. Epidemiology of autism: overview and issues outstanding. In: Handbook of autism and pervasive developmental disorders (Cohen DJ, Volkmar FR, eds), Ed 2, pp 41-46. New York: Wiley, 1997.

16. Ehlers S, Gillberg C. The epidemiology of Asperger syndrome: a total population study. J Child Psychol Psychiatry 34:1327-1350, 1993.

17. Wing L, Gould J Severe impairments of social interaction and associated abnormalities in children: epidemiology and classification. J Autism Dev Disord 9:11-29, 1979.

18. McLennan JD, Lord C, Schopler E. Sex differences in higher functioning people with autism. J Autism Dev Disord 23:217-227, 1993.

19. Volkmar FR, Szatmari P, Sparrow SS. Sex differences in pervasive developmental disorders. J Autism Dev Disord 23:579-591, 1993.

20. Allen DA. Autistic spectrum disorders: clinical presentation in preschool children. J Child Neurol 3 (Suppl):S48-S56, 1988.

21. Wing L. The continuum of autistic disorders. In: Diagnosis and assessment in autism (Schopler E, Mesibov GM, eds), pp 91-110. New York: Plenum, 1988.

22. Wing L. The autistic spectrum. Lancet 350:1761-1766, 1997.

23. Porter B, Goldstein E, Galil A, Carel C. Diagnosing the 'strange' child. Child Care Health Dev 18:57-63, 1992.

24. Deb S, Prasad KB. The prevalence of autistic disorder among children with a learning disability. Br J Psychiatry 165:395-399, 1994.

25. Bhaumik S, Branford D, McGrother C, Thorp C. Autistic traits in adults with learning disabilities. Br J Psychiatry 170:502-506, 1997.

26. Jensen VK, Larrieu JA, Mack KK. Differential diagnosis between Attention-Deficit/ Hyperactivity Disorder and Pervasive
Developmental Disorder-Not Otherwise Specified. Clin Pediatr 36:555-561, 1997.

27. Filipek PA, Accardo PJ, Baranek GT, Cook EH Jr, Dawson G, Gordon B et al. The screening and diagnosis of autistic spectrum disorders. J Autism Dev Disord 29:437-482, 1999.

28. Hirtz D, Wagner A, Filipek PA. The autistic spectrum disorders. In: Pediatric neurology: principles and practice (Swaiman KF, Ashwal S, Ferreiro DM, eds), Ch 37. Philadelphia: WB SaundersMosby, 2006.

29. Volkmar FR, Paul R, Klin A, Cohen DJ, eds. Handbook of autism and pervasive developmental disorders, Ed 3. New York: Wiley, 2005.

30. Lord C, Bristol-Power M, Cafiero JM, Filipek PA, Gallagher JJ, Harris SL et al. Educating children with autism. Report of the Committee on Educational Interventions for Autistic Children (Lord C, McGee JP, eds). Washington, DC: National Academy of Science, National Academies Press, 2001.

31. JADD Special Issue: NAS Workshop Papers. J Autism Dev Disord 32:349-508, 2002.

32. Steinbrook R. Testing medications in children. $N$ Engl $J$ Med 347:1462-1470, 2002.

33. Blumer JL. Off-label uses of drugs in children. Pediatrics 104: 598-602, 1999.

34. Filipek PA. Medical aspects of autism. In: Handbook of autism and pervasive developmental disorders (Volkmar FR, Klin A, Paul R, Cohen DJ, eds) Ch 20, pp 534-578. New York: Wiley, 2005

35. McDougle CJ, Posey DJ. Genetics of childhood disorders: XLIV Autism. Part 3: Psychopharmacology of autism. J Am Acad Child Adolesc Psychiatry 41:1380-1383, 2002.

36. Walkup JT, Labellarte MJ, Riddle MA, Pine DS, Greenhill L, Klein R et al. Fluvoxamine for the treatment of anxiety disorders in children and adolescents. N Engl J Med 344:1279-1285, 2001.

37. Lewis MH, Lazoritz M. Psychopharmacology of autism spectrum disorders. Psychiatric Times 22, 2005.

38. Aman MG, Lam KS, Van Bourgondien ME. Medication patterns in patients with autism: temporal, regional, and demographic influences. J Child Adolesc Psychopharmacol 15:116-126, 2005.

39. Martin A, Scahill L, Klin A, Volkmar FR. Higher-functioning pervasive developmental disorders: rates and patterns of psychotropic drug use. J Am Acad Child Adolesc Psychiatry 38:923-931, 1999.

40. Hollander E, Phillips A, Chaplin W, Zagursky K, Novotny S, Wasserman $\mathrm{S}$ et al. A placebo controlled crossover trial of liquid fluoxetine on repetitive behaviors in childhood and adolescent autism. Neuropsychopharmacology 30:582-589, 2005.

41. Buitelaar JK, Willemsen-Swinkels SH. Autism: current theories regarding its pathogenesis and implications for rational pharmacotherapy. Paediatrics Drugs 2:67-81, 2000.

42. Quintana H, Birmaher B, Stedge D, Lennon S et al. Use of methylphenidate in the treatment of children with autistic disorder. $J$ Autism Dev Disord 25:283-294, 1995.

43. Research Units on Pediatric Psychopharmacology Autism Network. Randomized, controlled, crossover trial of methylphenidate in pervasive developmental disorders with hyperactivity. Arch Gen Psychiatry 62:1266-1274, 2005.

44. McDougle CJ, Stigler KA, Posey DJ. Treatment of aggression in children and adolescents with autism and conduct disorder. J Clin Psychiatry 64:16-25, 2003.

45. Anderson LT, Campbell M, Adams P, Small AM, Perry R, Shell J The effects of haloperidol on discrimination learning and behavioral symptoms in autistic children. J Autism Dev Disord 19:227239, 1989.

46. McCracken JT, McGough J, Shah B, Cronin P, Hong D, Aman MG et al. Risperidone in children with autism and serious behavioral problems. N Engl J Med 347:314-321, 2002.

47. Shea S, Turgay A, Carroll A, Schulz M, Orlik H, Smith I et al. Risperidone in the treatment of disruptive behavioral symptoms in children with autistic and other pervasive developmental disorders. Pediatrics 114:e634-e641, 2004.

48. Di Martino A, Tuchman RF. Antiepileptic drugs:affective use in autism spectrum disorders. Pediatric Neurol 25:199-207, 2001.

49. Hellings JA, Weckbaugh M, Nickel EJ, Cain SE, Zarcone JR, Reese RM et al. A double-blind, placebo-controlled study of 
valproate for aggression in youth with pervasive developmental disorders. J Child Adolesc Psychopharmacol 15:682-692, 2005.

50. Owley T, Salt J, Guter S, Grieve A, Walton L, Ayuyao N et al. A prospective, open-label trial of memantine in the treatment of cognitive, behavioral, and memory dysfunction in pervasive de- velopmental disorders. J Child Adolesc Psychopharmacology (in press).

51. Filipek PA, Semrud-Clikeman M, Steingard RJ, Renshaw PF, Kennedy DN, Biederman J Volumetric MRI analysis comparing attention-deficit hyperactivity disorder and normal controls. $\mathrm{Neu}$ rology 48:589-601, 1997. 